\title{
Shedding Light on Retinoblastoma - A Review Article
}

\author{
Hamzeh Mohammad Alrawashdeh ${ }^{*}$, Omar Hamdan ${ }^{2}$, Nabeel M. Hasasna ${ }^{3}$, Islam J. Alzayadneh and Imene Ghoul $^{5}$ \\ 'Ophthalmology specialist, Amman Eye Clinic, Amman, Jordan \\ ${ }^{2}$ Assistant professor, Department of Pathology, Mutah University, Karak, Jordan \\ ${ }^{3}$ Department of Pathology, King Hussein Cancer Center, Amman, Jordan \\ ${ }^{4}$ Assistant professor, Department of Special Surgeries, Otolaryngology-Head and Neck Surgery, Mutah University, Karak, Jordan \\ ${ }^{5}$ Department of Pediatrics, Ibn Al Haytham Hospital, Amman, Jordan
}

\begin{abstract}
Retinoblastoma is the most frequent primary intraocular tumor in children aged under 15 years. Usually, the tumor discovered during infancy. However, it can also be observed in late childhood and early adulthood. In pregnancies with a high risk of retinoblastoma, genetic testing and antenatal ultrasonography is considered for intrauterine detection of the tumor.

The most common presenting signs in children are leukocoria followed by strabismus. Besides, nonspecific ocular signs that may simulate other tumors or retinal lesions may present. Hereditary retinoblastoma carries a high risk for secondary tumors such as sarcomas (osteosarcoma and soft-tissue sarcoma).

Previously, the late presentation and management of retinoblastoma holed a very poor prognosis with a high rate of morbidity and mortality. Nowadays, the early diagnosis and the current therapeutic methods carry a good prognosis for survival, globe salvage, and vision.
\end{abstract}

Keywords: Retinoblastoma, Leukocoria, Strabismus, Flexner-wintersteiner rosettes, Tumor-suppressor gene, Tumor staging.

\section{Introduction}

Retinoblastoma is an aggressive and rare tumor that develops rapidly from the immature cells of the retina. It is the most common and frequent intraocular tumor of childhood. Retinoblastoma may be congenital. However, it may not be recognized until the age of six months to two years. About $60 \%$ of cases are sporadic, and the rest are familial (autosomal dominant) with bilateral tumor presents in $30 \%$ of all cases. It is considered one of the tumors that draw attention to the genetic etiology of cancer. Worldwide, the incidence of retinoblastoma is one per 15000-20000 live births with no geographical or population preferences [1].

In unilateral involvement, five years survival is around $90 \%$, and slightly less in bilateral cases. The optic nerve, uveal or sclera invasion, as well as vitreous seeding, and anterior segment involvement, are considered to carry grave prognosis. Besides, extensive tumor and ocular necrosis are correlated with high-risk prognostic factors, while tumor differentiation does not seem to have prognostic significance [2].

Leukocoria, a white or pale pupillary reflex, is the most frequent presenting and warning sign [1]. It is the first manifestation of retinoblastoma in about $60 \%$ of cases with a high survival rate ( $88 \%$ at five years) but poor globe salvage. Strabismus is the second frequent presenting sign in about $20 \%$ of patients, which is a result of reduced vision in the affected eye due to macular involvement. Patients with retinoblastoma who present with squint have a high chance for survival and globe salvage in contrast to leukocoria [3]. The remaining $20 \%$ of presenting signs are late, atypical, and carry a poorer prognosis. These include inflamed eyes, neovascular glaucoma, hyphema, hypopyon, and orbital cellulitis. In developing countries, orbital or extraocular involvement with proptosis is the most common clinical presentation [4].

Many conditions may present as or simulate retinoblastoma. These may include congenital cataract, persistent fetal vasculature (PFV), retinopathy of prematurity (ROP), coats' disease, toxocariasis, myelinated retinal nerve fiber layer (MRNFL), vitreous hemorrhage, other retinal tumors or other ocular opacities that may present as leukocoria.

*Correspondence to: Hamzeh Mohammad Alrawashdeh, Ophthalmology specialist, Amman Eye Clinic, Amman, Jordan, Tel: +962797274355, E-mail: dr_hmsr@ yahoo.com

Citation: Alrawashdeh HM, Hamdan O, Hasasna NM (2020) Shedding Light on Retinoblastoma - A Review Article. J Clin Anat Pathol, 5(1): 105. DOI: https://doi. org/10.47275/2332-4864-105.

Received: July 23, 2020; Accepted: August 07, 2020; Published: August 09, 2020

Copyright: @ 2020 Alrawashdeh HM, et al. This is an Open Access article distributed under the terms of the Creative Commons Attribution 4.0 International License (CC-BY) (http://creativecommons.org/licenses/by/4.0/) which permits commercial use, including reproduction, adaptation, and distribution of the article provided the original author and source are credited. 


\section{Genetics}

In both non-heritable and heritable types of retinoblastoma, the initiation of tumor growth is caused by the biallelic mutations of the retinoblastoma tumor-suppressor gene (RB1 gene). In heritable retinoblastoma mutations in both alleles inactivate the negative growth regulator RB1 gene. A child is predisposed to the tumor by the first mutation in the RB1 gene, while the initiation of the cancer growth is related to somatic mutations in one or more retinal cells. These mutations are known as M1 and M2, respectively. Rarely, trilateral retinoblastoma resulted from primitive neuroectodermal tumors that arise in the suprasellar or pineal region, and carry a poor prognosis. Bilateral retinoblastoma is heritable. However, a small proportion of unilateral retinoblastoma can be transmitted to the next generation of the family [1].

In more than $95 \%$ of patients, bi-allelic inactivation of the RB1 gene on chromosome 13q14 is the main cause of intraocular retinoblastoma. The inactivation of the RB1 gene can be tumor-specific or somatic caused by a deletion or germline mutation that co-occurred with somatic inactivation of the remaining allele. Moreover, it may begin during early embryogenesis resulting in post-zygotic mosaicism. Children with constitutional mosaicism or germline mutation in the RB1 gene are predisposed to developing pinealoblastoma and sarcomas following radiation therapy [5,6]. Mostly in retinoblastoma, a two-step inactivation of both alleles of the RB1 gene is essential for its formation [7-9]. Nevertheless, some research considered this as a cause for non-proliferative retinoma, which needs more genetic aberrations to progress into retinoblastoma [9-11].

Recurrent chromosomal copy number alterations are the most frequent alterations that lead to tumor suppressor genes inactivation or oncogenes activation $[7,11,12]$. Recently, it has been proved that other mutations affecting the CREBBP and BCOR transcriptional regulatory genes play a role in rare subtypes of retinoblastomas [7]. Furthermore, focal high-level amplification of the MYCN oncogene was found to be a cause in about $2 \%$ of retinoblastoma cases $[7,13]$. RB1 gene alterations include chromosomal deletions, rearrangements involving the whole gene, and single nucleotide changes.

Both array comparative genomic hybridization (aCGH) and high-throughput next-generation sequencing (NGS) are modern techniques the have a significant role in enhancing the specificity and sensitivity of mutations detection. However, a large spectrum of collaborative mutations is not well recognised yet [12].

The current development in DNA sequencing technologies replaced older expensive and time-consuming methods and made the molecular diagnosis and follow-up part of the routine workup in clinical medicine. Next-generation sequencing (NGS) technology is currently the latest method used to detect point mutations in genes that can cause retinoblastoma as RB1 gene, neuroblastoma MYC (NMYC) oncogene, and more recently additional likely pathogenic alterations beyond the previously mentioned genes. Higher histologic grade and anaplasia are aggressive histopathological features associated with the presence of further pathogenetic mutations other than inactivation of the RB1 gene and can be seen in both unilateral and sporadic disease [14].

\section{Clinical and Pathological Findings}

\section{Clinical findings}

Factors that have a major influence in the clinical presentation of retinoblastoma are the duration of the tumor, growth pattern (endophytic, exophytic, and mixed growth), vascularization degree, seeding of vitreous, as well as the presence of exudative retinal detachment, calcifications, and/ or intraocular hemorrhage [15].

The endophytic growth pattern shows a growth of the tumor towards the vitreous after the division of cells inside the internal layers of the retina with a high propensity for vitreous seeding. The exophytic pattern shows cells division inside the external layers of the retina in the subretinal space under the retina resulting in an exudative detachment. In mixed growth pattern, the features of the previous two patterns are present [15].

A very rare diffuse infiltrating (plaque-like) form of retinoblastoma presents as an irregular flat lesion on or beneath the retinal surface without calcifications. With time, it diffuses anteriorly reaching the anterior segment presents as pseudoinflammation (pseudohypopyon) in the late stages [15].

\section{Pathological findings}

Retinoblastoma has a marked tendency to invade the optic nerve and uveal tract. This is seen commonly in exophytic tumors associated with secondary glaucoma (Figure 1). Furthermore, distant metastases to the cranial vault and skeletal system may occur.

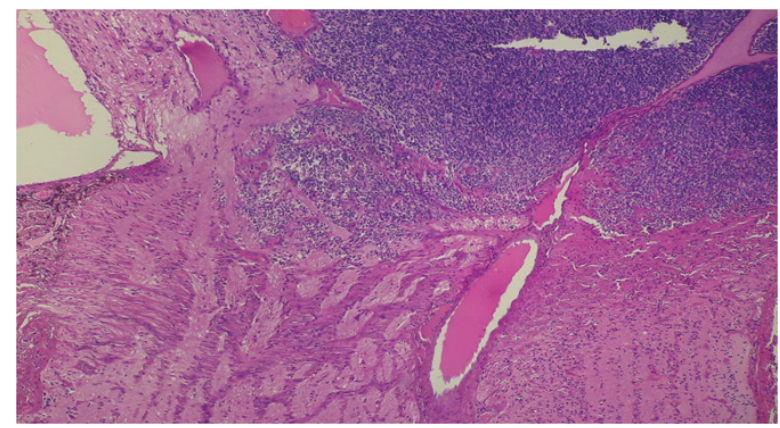

Figure 1: Low power view (10X) shows invasion of optic nerve base. 


\section{Gross description}

Macroscopically, the tumor appears either endophytic (growth pattern toward the retina) (Figure 2a, 2b, 2c) or exophytic (growth pattern toward the choroid) (Figure 3a, 3b, 3c), and in rare cases, it appears diffusely infiltrative. The cut section reveals a white cut surface with yellowish areas due to necrosis.

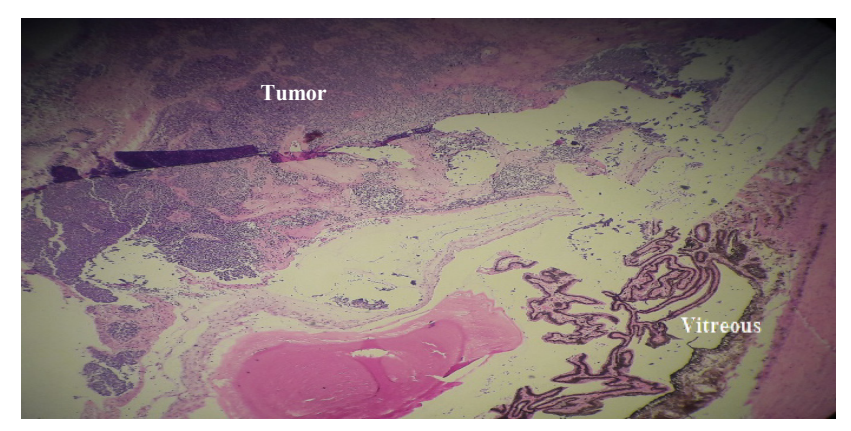

Figure 2a: Low power view (10X) shows endophytic tumor growth toward the vitreous.

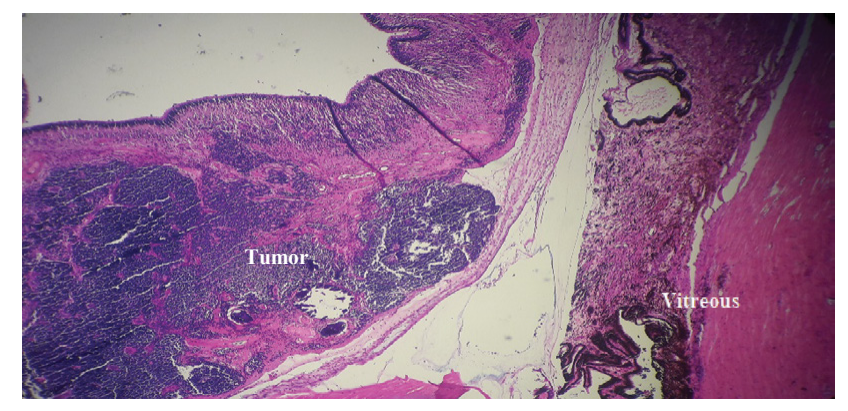

Figure 2b: Intermediate power view (20X) shows endophytic tumor growth.

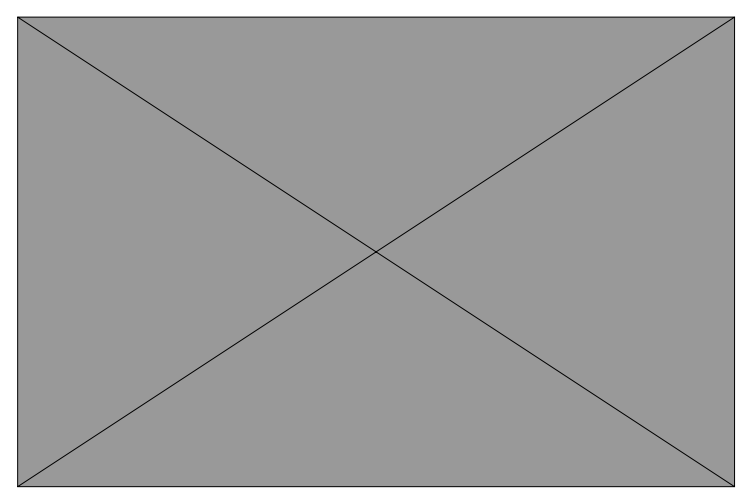

Figure 2c: Cross-section of the eye globe demonstrates endophytic tumor growth (slide view).

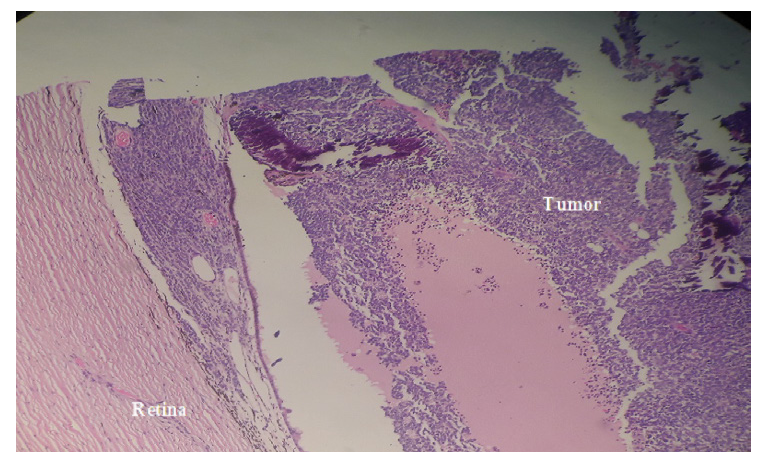

Figure 3a: Low power view (10X) shows exophytic tumor growth toward the subretinal space. 


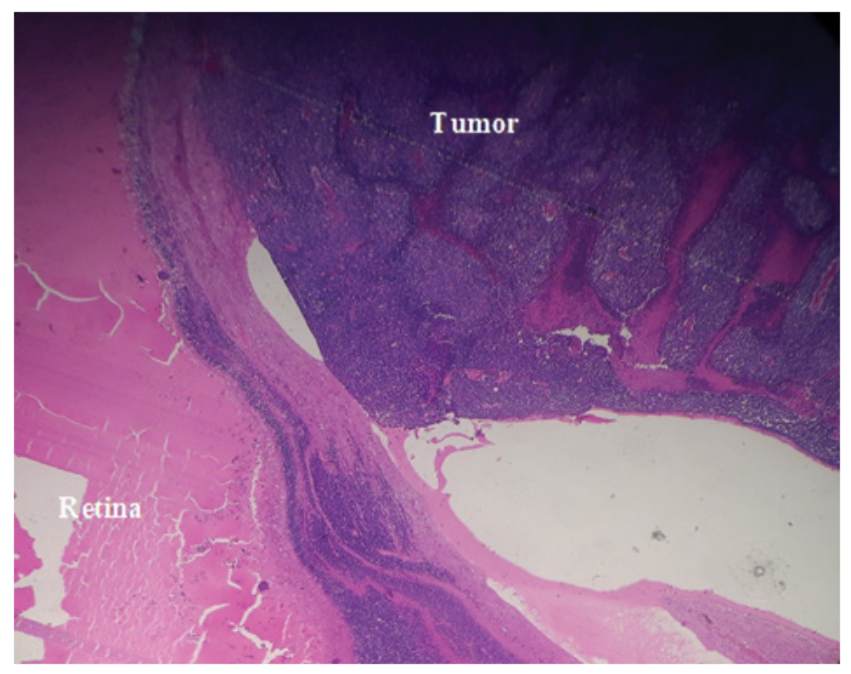

Figure 3b: Intermediate power view (20X) shows exophytic tumor growth.

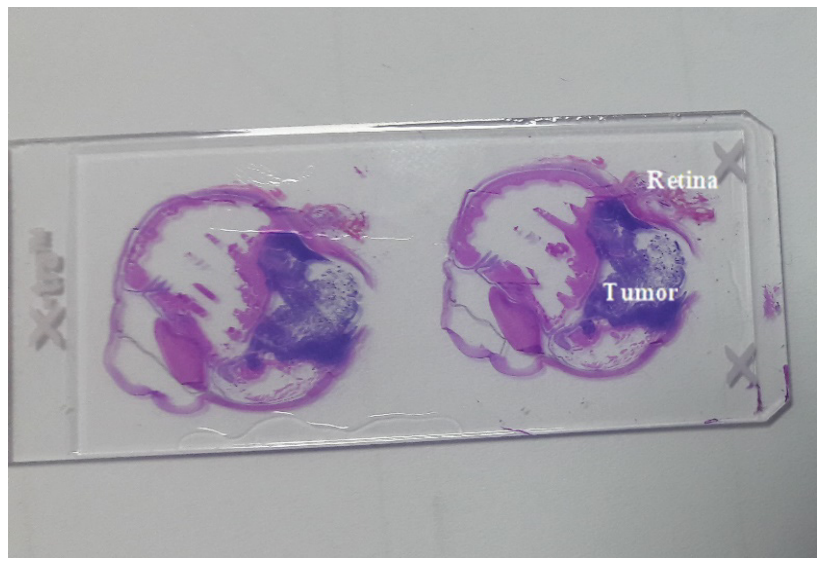

Figure 3c: Cross-section of the eye globe demonstrates exophytic tumor growth (slide view).

\section{Microscopic description}

Histologically, retinoblastoma is consist of trabeculae, sheets, and nests of small blue cells. These cells are characterized by hyperchromatic nuclei with scanty cytoplasm and stroma (Figure 4). Also, calcifications along with tumor necrosis can present away from vessels (Figure 5).

Cells that surround hollow lumen, and outlined by an eosinophilic circle consists of terminal strips similar to the retinal outer limiting membrane (OLM) are known as Flexner-Wintersteiner rosettes (Figure 6). Homer-Wright rosettes that represent the displaced nuclei away from the empty lumen are also seen (Figure 7). Moreover, Azzopardi phenomena (basophilic deposits around blood vessels), variable apoptotic cells (Figure 8), and frequent mitotic figures (Figure 9) can be noticed [2].

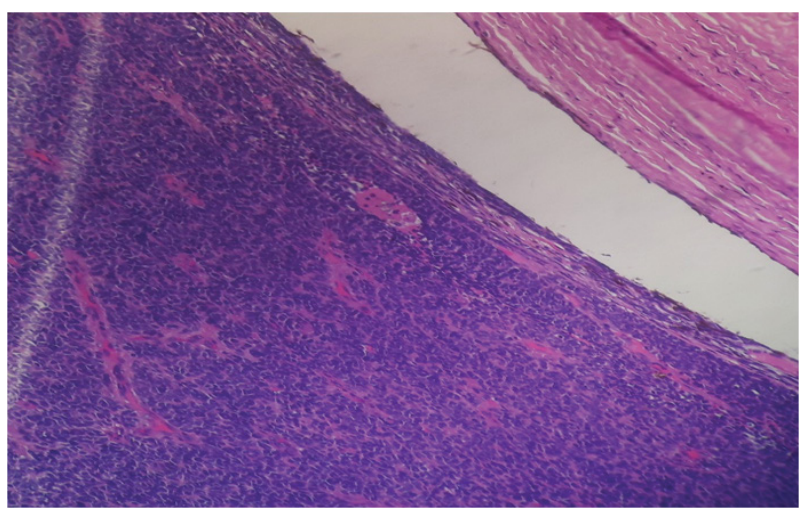

Figure 4: Low power view (10X) shows small round blue tumor cells. 


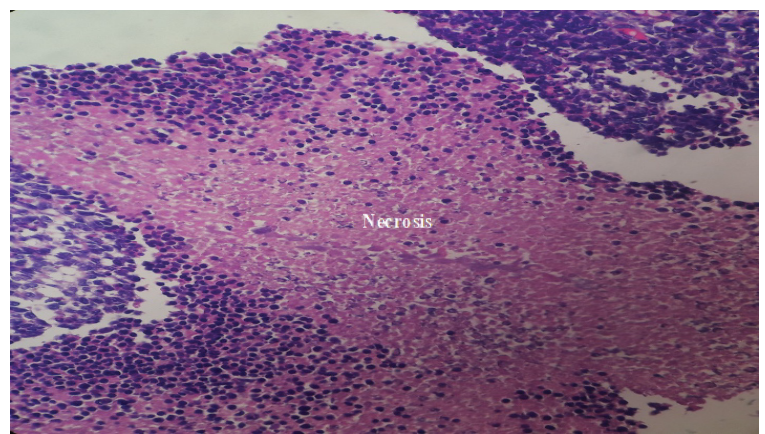

Figure 5: Low power view (10X) shows a prominent large area of necrosis away from blood vessels.

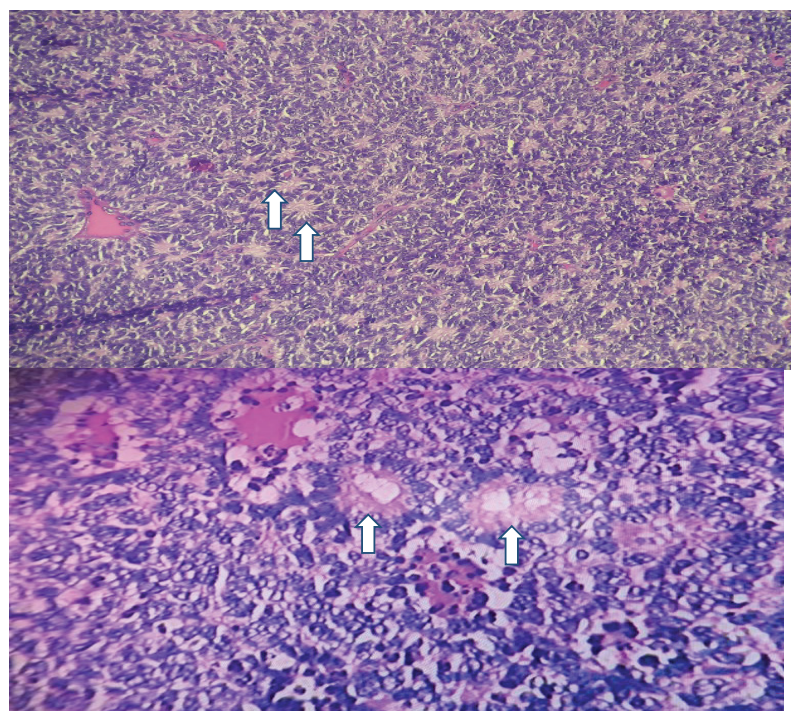

Figure 6: Low (10X) and high power view (40X) show multiple Flexner-Wintersteiner rosettes (Arrows).

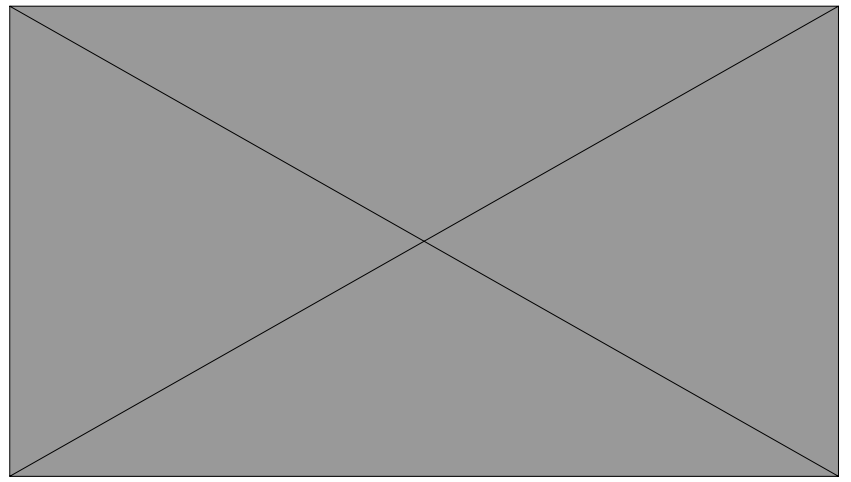

Figure 7: Intermediate power view (20X) shows multiple Homer-Wright rosette (Arrows).

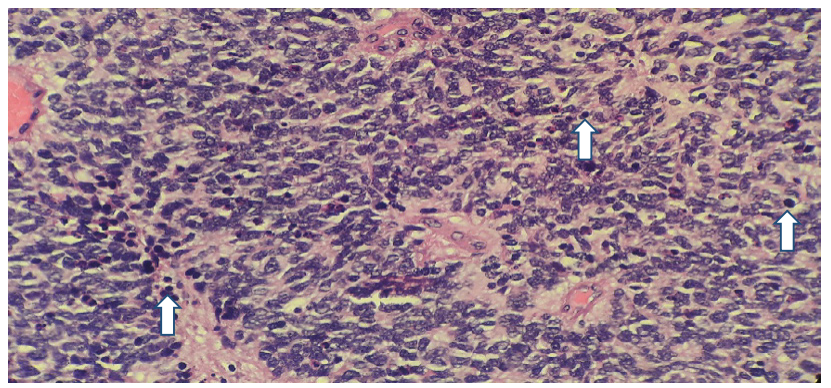

Figure 8: High power view (40X) shows multiple apoptotic bodies (Arrows). 


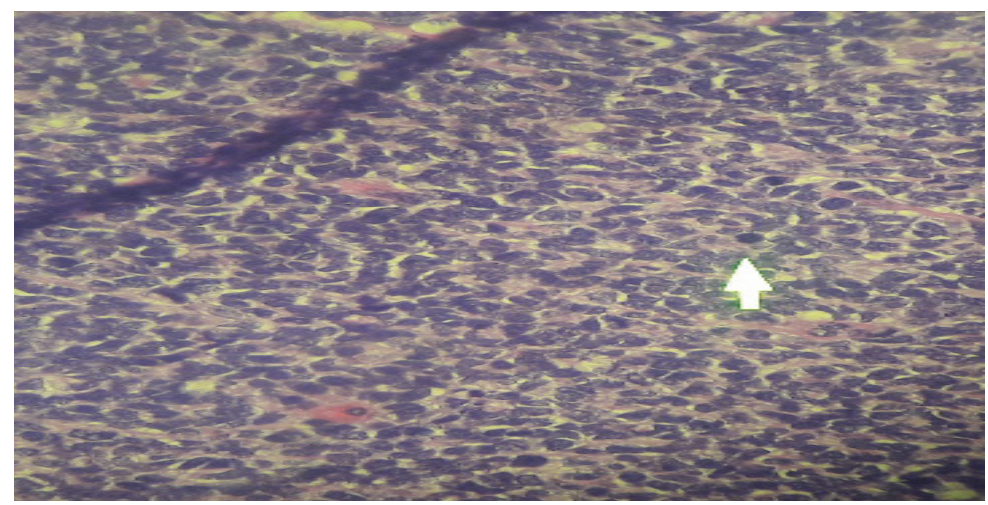

Figure 9: High power view (40X) shows multiple mitotic figures (Arrow).

\section{Histological stains}

Positive pathology stains include neuron-specific enolase, synaptophysin, S100, Leu7, and GFAP immunostains with high Ki-67 mitotic index.

\section{Categorization of retinoblastoma}

1. Differentiated retinoblastoma, which shows bipolar-like cells with multiple rosettes (Figure 10).

2. Undifferentiated retinoblastoma, which shows anaplastic and large cells. The absence of rosette formation is the hallmark of this type (Figure 11).

3. Retinocytoma, which shows remarkable benign differentiation of photoreceptor with less nuclear hyperchromasia and abundant cytoplasm. Besides, there is no necrosis or mitotic activity [2].

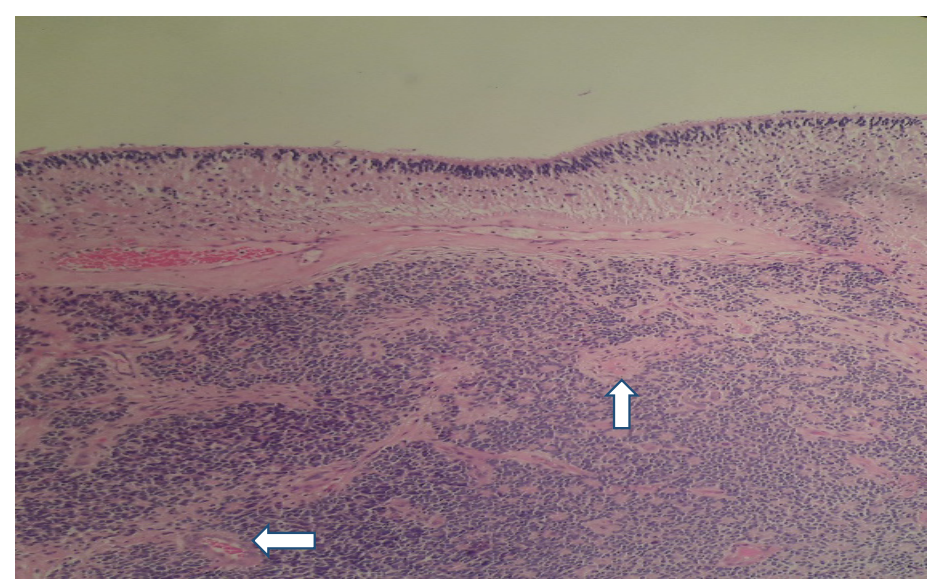

Figure 10: Low power view (10X) shows multiple rosettes owing to well-differentiated retinoblastoma (Arrows).

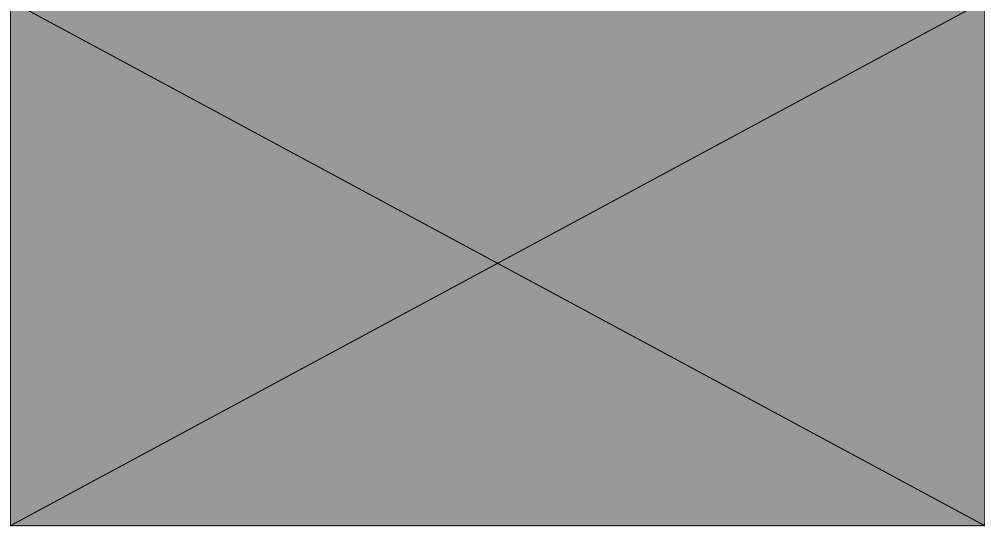

Figure 11: Low power view (10x) shows poorly differentiated small round blue cells. 
Citation: Alrawashdeh HM, Hamdan O, Hasasna NM (2020) Shedding Light on Retinoblastoma - A Review Article. J Clin Anat Pathol, 5(1): 105. DOI: https://doi. org/10.47275/2332-4864-105.

\section{Staging \\ Clinical staging}

In 1963, the Reese-Ellsworth Classification was established on the bases of the intraocular staging of retinoblastoma and prognostication of globe salvage following external beam radiotherapy. However, it does not consider survival (Table 1). From that time, many staging protocols were proposed, of which the International Intraocular Retinoblastoma Classification (ICRB /ABC Classification) has the best prognostic value, and it is the most commonly used protocol among ophthalmologists [16, 17].

Table 1: Reese-Ellsworth classification system.

\begin{tabular}{|l|l|l|}
\hline \multicolumn{1}{|c|}{ A } & \multicolumn{1}{|c|}{ B } \\
\hline Group 1(Very Favorable) & Solitary tumor < 4 DD in size, at or behind the equator. & Multiple tumors, none $>$ 4 DD in size, all at or behind the equator \\
\hline Group 2 (Favorable) & Solitary tumor, 4 to 10 DD in size, at or behind the equator. & Multiple tumors, 4 to 10 DD in size, behind the equator. \\
\hline Group 3 (Doubtful) & Any tumor anterior to the equator. & Solitary tumor, > 10 DD, behind the equator. \\
\hline Group 4 (Unfavorable) & Multiple tumors, some > 10 DD in size. & Any lesion extending anteriorly to the ora serrata. \\
\hline Group 5 (Very Unfavorable) & Massive tumor involving over half of the retina. & Vitreous seeding. \\
\hline
\end{tabular}

$\mathrm{DD}=$ Disc diameter

From "Ophthalmology Review Manual" [18]

Shifting from external beam radiotherapy to chemotherapy as the preferred modality of treatment in the 1990s, due to the high probability of secondary tumors appearance after external beam radiotherapy, makes the Reese-Ellsworth classification system incapable of reflecting the prognostic value of these modern modalities of treatment. Therefore, the International intraocular retinoblastoma classification was designed to determine patients, who are liable to be cured without external beam radiation therapy or enucleation (Table 2).

Table 2: International intraocular retinoblastoma classification (ABC classification).

\begin{tabular}{|l|l|}
\hline Group A & Small intraretinal tumors $\leq 3 \mathrm{~mm}$, at least $3 \mathrm{~mm}$ away from the foveola and $1.5 \mathrm{~mm}$ from the optic disc without subretinal or vitreous seeding. \\
\hline Group B & $\begin{array}{l}\text { Tumors }>3 \mathrm{~mm},<3 \mathrm{~mm} \text { from the foveola and }<1.5 \mathrm{~mm} \text { from the optic disc without subretinal or vitreous seeding, or with subretinal fluid with no more than } 5 \mathrm{~mm} \\
\text { from the base of the tumor. }\end{array}$ \\
\hline Group C & Any size of the tumor with focal vitreous or subretinal seeding within $3 \mathrm{~mm}$ or more from tumor, or subretinal fluids involving up to one quarter of the retina. \\
\hline Group D & Tumor with diffuse vitreous or subretinal seeding $>3 \mathrm{~mm}$ from the tumor, or retinal detachment of more than one quadrant. \\
\hline Group E & $\begin{array}{l}\text { Extensive retinoblastoma occupying }>50 \% \text { of the globe, with or without irreversible neovascular glaucoma, massive hemorrhage, aseptic orbital cellulitis, an extension } \\
\text { of tumor anterior to vitreous face, optic nerve, lens, and anterior chamber. }\end{array}$ \\
\hline
\end{tabular}

*Linn Murphree A. Intraocular retinoblastoma: the case for a new group classification[16].

This classification consists mainly of five groups named A, B, C, D, and E (group A carries the best prognosis and E the worst). It takes in to account the tumor size, its proximity to the macula and optic disc, presence and degree of seeding, retinal detachment and late complications such as hemorrhage, neovascular glaucoma, the extension to the optic nerve or anterior chamber involvement [17].

\section{Pathological staging}

The International Union for Cancer Control (UICC) and the American Joint Committee on Cancer (AJCC) are the official institutions responsible for preparing and maintaining the TNM system for classification of malignant tumors. Nowadays, it is the most frequently used staging system among ophthalmic pathologist. This globally recognized classification is based on the anatomical extent of the primary tumor, the involvement of regional lymph nodes, and the presence of distant metastases, which is coded by $\mathrm{T}, \mathrm{N}$, and $\mathrm{M}$, respectively. Table 3 and 4 show the $7^{\text {th }}$ and the most recent 8 th edition to emphasize the current modifications in the new staging system (Tables 3 and 4 ).

Table 3: TNM7 staging of retinoblastoma.

\begin{tabular}{|c|c|}
\hline \multicolumn{2}{|c|}{ Primary Tumor (pT) } \\
\hline pTX & Primary tumor cannot be assessed. \\
\hline po & No evidence of primary tumor. \\
\hline$p T 1$ & Tumor confined to the eye with no optic nerve or choroidal invasion. \\
\hline$p T 2$ & Tumor with minimal optic nerve and/or choroidal invasion. \\
\hline$p T 2 a$ & Tumor superficially invades optic nerve head but does not extend posterior to lamina cribrosaor tumor exhibits focal choroidal invasion. \\
\hline$p T 2 b$ & Tumor superficially invades optic nerve head but does not extend posterior to lamina cribrosaand exhibits focal choroidal invasion. \\
\hline pT3 & Tumor with significant optic nerve and/or choroidal invasion. \\
\hline$p T 3 a$ & Tumor invades optic nerve posterior to lamina cribrosa but not to surgical resection line $o r$ tumor exhibits massive choroidal invasion. \\
\hline$p T 3 b$ & Tumor invades optic nerve posterior to lamina cribrosa but not to surgical resection line and exhibits massive choroidal invasion. \\
\hline pT4 & Tumor invades optic nerve to resection line or exhibits extra-ocular extension elsewhere. \\
\hline pT4a & Tumor invades optic nerve to resection line but no extra-ocular extension identified. \\
\hline$p T 4 b$ & Tumor invades optic nerve to resection line and extra-ocular extension identified. \\
\hline \multicolumn{2}{|c|}{ Regional Lymph Nodes (pN) } \\
\hline$p N X$ & Regional lymph nodes cannot be assessed. \\
\hline pNO & No regional lymph node involvement. \\
\hline pN1 & Regional lymph node involvement (preauricular, cervical, or submandibular). \\
\hline
\end{tabular}


Citation: Alrawashdeh HM, Hamdan O, Hasasna NM (2020) Shedding Light on Retinoblastoma - A Review Article. J Clin Anat Pathol, 5(1): 105. DOI: https://doi. org/10.47275/2332-4864-105.

\begin{tabular}{|l|l|}
\hline$p N 2$ & Distant lymph node involvement. \\
\hline \multicolumn{2}{|l|}{ Distant Metastasis (pM) } \\
\hline$c M 0$ & No metastasis. \\
\hline$p M 1$ & Metastasis to sites other than CNS. \\
\hline$p M 1 a$ & Single lesion. \\
\hline$p M 1 b$ & Multiple lesions \\
\hline$p M 1 c$ & CNS metastasis. \\
\hline$p M 1 d$ & Discrete mass(es) without leptomeningeal and/or CSF involvement. \\
\hline$p M 1 e$ & Leptomeningeal and/or CSF involvement. \\
\hline
\end{tabular}

"Pathologic TNM staging of retinoblastoma. The American Joint Committee on Cancer (AJCC), 7th edition [19].

Table 4: TNM8 staging of retinoblastoma

\begin{tabular}{|c|c|}
\hline \multicolumn{2}{|c|}{ Primary Tumor (pT) } \\
\hline pTX & Unknown evidence of intraocular tumor. \\
\hline pT0 & No evidence of intraocular tumor. \\
\hline pT1 & Intraocular tumor(s) without any local invasion, focal choroidal invasion, or pre- or intralaminar involvement of the optic nerve head. \\
\hline$p T 2$ & Intraocular tumor(s) with local invasion. \\
\hline$p T 2 a$ & Concomitant focal choroidal invasion and pre- or intralaminar involvement of the optic nerve head. \\
\hline$p T 2 b$ & Tumor invasion of iris stroma and/or trabecular meshwork and/or Schlemm's canal. \\
\hline pT3 & Intraocular tumor(s) with significant local invasion. \\
\hline pT3a & $\begin{array}{l}\text { Massive choroidal invasion ( }>3 \mathrm{~mm} \text { in largest diameter, or multiple foci of focal choroidal involvement totaling }>3 \mathrm{~mm} \text {, or any full-thickness choroidal } \\
\text { involvement). }\end{array}$ \\
\hline$p T 3 b$ & Retrolaminar invasion of the optic nerve head, not involving the transected end of the optic nerve. \\
\hline$p T 3 c$ & Any partial-thickness involvement of the sclera within the inner two thirds. \\
\hline$p T 3 d$ & Full-thickness invasion into the outer third of the sclera and/or invasion into or around emissary channels. \\
\hline pT4 & $\begin{array}{l}\text { Evidence of extraocular tumor: tumor at the transected end of the optic nerve, tumor in the meningeal spaces around the optic nerve, full-thickness invasion of } \\
\text { the sclera with an invasion of the episclera, adjacent adipose tissue, extraocular muscle, bone, conjunctiva, or eyelids. }\end{array}$ \\
\hline \multicolumn{2}{|c|}{$\begin{array}{l}\text { Regional Lymph Nodes } \\
(p N)\end{array}$} \\
\hline$p N X$ & Regional lymph nodes cannot be assessed. \\
\hline pNO & No regional lymph node involvement. \\
\hline$p N 1$ & Regional lymph node involvement. \\
\hline \multicolumn{2}{|c|}{ Distant Metastasis (pM) } \\
\hline pM1 & Distant metastasis with histopathologic confirmation. \\
\hline pM1a & Histopathologic confirmation of tumor at any distant site (eg, bone marrow, liver, or other). \\
\hline pM1b & Histopathologic confirmation of tumor in the cerebrospinal fluid or CNS parenchyma. \\
\hline
\end{tabular}

\section{Management of Intraocular Retinoblastoma}

In the early 1990s, the chance for survival for patients with retinoblastoma was very low. An improvement in the survival rate among patients was noticed from $30 \%$ up to $80 \%$ between the 1930 s and 1960 s due to the continuous improvements in the management of retinoblastoma. Nowadays, about $95 \%$ of patients had a high chance to survive due to the modern treatment modalities and treatment strategies, especially in developed countries that have advanced specialized centers [17].

The main aim of treatment is saving lives, along with salvage of globe and obtaining the best potential vision. This should always be considered side by side to a constant re-evaluation of patients and their response to different treatment modalities.

\section{Medical Treatment}

\section{Intravenous chemotherapy}

Chemo-reduction treatment consists of thermotherapy, focal consolidative therapy (laser), and cryotherapy with the administration of systemic chemotherapy. This leads to shrinkage of tumors and increases the success of focal therapies [21]. Focal therapy can destruct the tumor cells and increase the penetration of chemotherapeutic agents into eyes due to breaking down of the blood ocular barrier [22]. The mainly used chemotherapeutic agents are vincristine, carboplatin, and etoposide.

\section{Intra-arterial chemotherapy}

Administration of intra-arterial chemotherapeutic agents has been practiced recently. In 2008, Abramson et al. modified the Japanese protocol of cannulation of the carotid artery to deliver anticancer agents to the eye through the ophthalmic artery. This technique is known as supra-selective intra-arterial chemotherapy. A good response was noticed using Melphalan as a chemotherapeutic agent for this technique [23].

\section{Intravitreal chemotherapy}

Some eyes have residual or refractory vitreous seeds despite systemic intravenous chemotherapy or intra-arterial chemotherapy. These eyes 
Citation: Alrawashdeh HM, Hamdan O, Hasasna NM (2020) Shedding Light on Retinoblastoma - A Review Article. J Clin Anat Pathol, 5(1): 105. DOI: https:/doi. org/10.47275/2332-4864-105.

have been successfully treated with intravitreal chemotherapy with 20 to $30 \mu \mathrm{g}$ of melphalan hydrochloride along with double or triple freeze-thaw to the injection site to destroy any tumor cells that may attempt to travel along the needle track [24].

Also, a combination of $40 \mu \mathrm{g}$ of melphalan hydrochloride (in $0.04 \mathrm{~mL}$ ) and 8-20 $\mu \mathrm{g}$ of topotecan hydrochloride (in $0.04 \mathrm{~mL}$ ) was proved to be safe and efficient for refractory or recurrent vitreous seeds [25].

\section{Radiation Treatment}

If retinoblastoma remains uncontrolled after the chemotherapy options, external beam radiation and plaque radiotherapy are considered the second option for treatment. Radioactive plaques include Ruthenium-106 and Iodine-125, which is the most widely used plaque [17].

A custom made radioactive plaque is surgically sutured onto the sclera directly on top of the site of intraocular retinoblastoma to target the active tumor in an attempt to spare normal retina and optic nerve. After a set period, the plaque is removed.

Stereotactic conformal radiotherapy and accelerated proton beam irradiation are also known methods for the treatment of retinoblastoma [17].

\section{Surgical Treatment}

Enucleation is considered for group E eyes and eyes that are not responding to conservative treatments. In addition, advanced group D or E eyes with high probability for the extraocular spread and no hope for salvage of vision are candidates for primary enucleation[26].

\section{Screening}

Screening and genetic testing for retinoblastoma found to be very beneficial to achieve the best outcomes in terms of vision and the overall survival.

Any individual with a positive family history of retinoblastoma in at least one of his parents, siblings, or second-degree relatives is considered at risk of having the tumor, and defined as "patient at risk" [27]. Based on their expected risk to have the tumor children with a family history of retinoblastoma can be further categorized into a high, intermediate, and low-risk categories using genetic testing and counselling. Children with high risk require more frequent examinations, which are better to be performed under anesthesia.

For all children with a high risk, screening with sequent dilated fundus examination by an experienced ophthalmic oncologist is recommended from birth until the age of 7 years. No further follow-ups are needed for asymptomatic children after the age of 7 years, except for those who are known to have a mutation in the RB1 gene. This category of RB1 mutation carrier is recommended to be screened indefinitely every one to two years after the age of 7 years [27].

\section{Follow up}

Patients treated with chemo-reduction or/ and external beam radiation therapy need regular follow-up. The regression of the tumor is evaluated during each exam by the documentation of the tumor size, anatomical location, appearance, and the number of tumors if more than one tumor is noticed. Tumors that appear as white, calcific or translucent mass indicates regression. Occasionally, a flat scar can be noticed after proper treatment.

Until the age of three years, examinations under general anaesthesia is recommended every six to eight weeks and less frequent examinations with treated quiescent tumors. Always during follow-ups, attention to the possibility of secondary malignancies in patients with hereditary retinoblastoma should be considered.

\section{Conclusion}

In children with leukocoria and/ or strabismus, retinoblastoma should be excluded. Early diagnosis and treatment of retinoblastoma are crucial to save the vision, globe, and life. Patients with a positive family history should raise the attention to screen all family members and newborns at birth. Genetic testing and special monitoring using antenatal ultrasonography are required during pregnancy for families with a high risk of retinoblastoma.

Pediatrician, obstetricians, parents and health care providers are most likely the first to notice leukocoria, strabismus, or any other ocular signs. Thus, they should refer patients promptly to an ophthalmologist for evaluation and assessment. Management of patients with retinoblastoma needs a multidisciplinary specialized team and restrict follow-ups.

\section{Acknowledgements}

None.

\section{References}

1. Dimaras H, Kimani K, Dimba EA, Gronsdahl P, White A, et al. 2012. Retinoblastoma. Lancet 379(9824):1436-1446.https://doi.org/10.1016/S0140-6736(11)61137-9

2. Pernick N. Retinoblastoma. Accessed: July 19th 2020.

3. Beaverson K, Abramson DH, Lee TC, Hochberg HM, Kirszrot J, et al. 2001. In: Keunen JEE, Imhof SM, de Keizer RJW, Moll AC (eds). Xth International Congress of Ocular Oncology Amsterdam, Conference Proceedings, published by the eds 202.Return. 
Citation: Alrawashdeh HM, Hamdan O, Hasasna NM (2020) Shedding Light on Retinoblastoma - A Review Article. J Clin Anat Pathol, 5(1): 105. DOI: https://doi. org/10.47275/2332-4864-105.

4. Chan KW, Raney RB. 2005. Pediatric oncology, Springer, USA, pp 144.

5. Kleinerman RA, Yu CL, Little MP, Yi Y, Abramson D, et al. 2012. Variation of second cancer risk by family history of retinoblastoma among long-term survivors. J Clin Oncol 30(9):950957.https://doi.org/10.1200/JCO.2011.37.0239

6. Wong JR, Morton LM, Tucker MA, Abramson DV, Seddon JM, et al. 2014. Risk of subsequent malignant neoplasms in long-term hereditary retinoblastoma survivors after chemotherapy and radiotherapy. J Clin Oncol 32(29):3284-3290.https://doi.org/10.1200/JCO.2013.54.7844

7. Kooi IE, Mol BM, Massink MP, Ameziane N, Meijers-Heijboer H, et al. 2016. Somatic genomic alterations in retinoblastoma beyond RB1 are rare and limited to copy number changes. Sci Rep 6:25264.https://doi.org/10.1038/srep25264

8. Knudson AG Jr. 1971. Mutation and cancer: statistical study of retinoblastoma. ProcNatlAcadSci U S A. 68(4):820-823.https://doi.org/10.1073/pnas.68.4.820

9. Gallie BL, Campbell C, Devlin H, Duckett A, Squire JA. 1999. Developmental basis of retinal-specific induction of cancer by RB mutation. Cancer Res 59(7 Suppl):1731s-1735s. PMID: 10197588

10. Corson TW, Gallie BL. 2007. One hit, two hits, three hits, more? Genomic changes in the development of retinoblastoma. Genes Chromosomes Cancer 46(7):617-634.https://doi. $\operatorname{org} / 10.1002 / \mathrm{gcc} .20457$

11. Bowles E, Corson TW, Bayani J, Squire JA, Wong N, et al. 2007. Profiling genomic copy number changes in retinoblastoma beyond loss of RB1. Genes Chromosomes Cancer46(2):118-129. https://doi.org/10.1002/gcc.20383

12. Kooi IE, Mol BM, Massink MP, Jong MC, Graaf P, et al. 2016. A meta-analysis of retinoblastoma copy numbers refines the list of possible driver genes involved in tumor progression. PLoS One 11(4):e0153323.https://doi.org/10.1371/journal.pone.0153323

13. Rushlow DE, Mol BM, Kennett JY, Yee S, Pajovic S, et al. 2013. Characterisation of retinoblastomas without RB1 mutations: genomic, gene expression, and clinical studies. LancetOncol 14(4):327-334.https://doi.org/10.1016/S1470-2045(13)70045-7

14. Afshar AR, Pekmezci M, Bloomer MM, Cadenas NJ, Stevers M, et al. 2020. Next-generation sequencing of retinoblastoma identifies pathogenic alterations beyond rb1 inactivation thatcorrelate with aggressive histopathologic features. Ophthalmology 127(6):804-813.https://doi.org/10.1016/j.ophtha.2019.12.005

15. Abramson DH, Melson MR, Dunkel IJ, Frank CM. 2001. Third (fourth and fifth) nonocular tumors in survivors of retinoblastoma. Ophthalmology 108(10):1868-1876.https://doi. org/10.1016/s0161-6420(01)00713-8

16. Linn Murphree A. 2005. Intraocular retinoblastoma: the case for a new group classification. Ophthalmol Clin North Am 18(1):41-53.https://doi.org/10.1016/j.ohc.2004.11.003

17. Balmer A, Zografos L, Munier F. 2006. Diagnosis and current management of retinoblastoma. Oncogene. 25(38):5341-5349.https://doi.org/10.1038/sj.onc.1209622

18. Zegans MA, Chern KC. 2000. Ophthalmology review manual. Lippincott Williams \& Wilkins, USA, pp 483.

19. Edge SB, Compton CC. 2010. The American joint committee on cancer: the 7th edition of the AJCC cancer staging manual and the future of TNM. Ann Surg Oncol 17(6):1471-1474. https://doi.org/10.1245/s10434-010-0985-4

20. Mallipatna A, Gallie BL, Chévez-Barrios P, et al. 2017. Retinoblastoma. In: Amin MB, Edge SB, Greene FL (eds) AJCC Cancer Staging Manual. 8th ed. Springer, New York, NY,USA, pp 819-831.

21. Shields JA, Shields CL, De Potter P. 1993. Hydrooxyapatite orbital Implant after enucleation for intraocular tu. Int Ophthalmol Clin 33(3):95-99.https://oi.org/10.1097/00004397199303330-00014

22. Abramson DH, Frank CM, Chantada GL, de Totah AB, de Pifano IT, et al. 1999. Intraocular carboplatin concentrations following intravenous administration for human intraocularretinoblastoma. Ophthalmic Genet 20(1):31-36.https://doi.org/10.1076/opge.20.1.31.2302

23. Abramson DH, Dunkel IJ, Brodie SE, Kim JW, Gobin YP. 2008. A phase I/II study of direct intraarterial (ophthalmic artery) chemotherapy with melphalan for intraocular retinoblastomainitial results. Ophthalmology 115(8):1398-1404.https://doi.org/10.1016/j.ophtha.2007.12.014

24. Shields CL, Manjandavida FP, Arepalli S, Kaliki S, Lally SE, Shields JA. 2014. Intravitreal melphalan for persistent or recurrent retinoblastoma vitreous seeds: preliminary results. JAMA Ophthalmology 132(3):319-325.https://doi.org/10.1001/jamaophthalmol.2013.7666

25. Ghassemi F, Shields CL, Ghadimi H, Khodabandeh A, Roohipoor R. 2014. Combined intravitreal melphalan and topotecan for refractory or recurrent vitreous seeding fromretinoblastoma. JAMA Ophthalmol 132(8):936-941.https://doi.org/10.1001/jamaophthalmol.2014.414

26. Chantada GL, Doz F, Orjuela M, Qaddoumi I, Sitorus RS, et al. 2008. World disparities in risk definition and management of retinoblastoma: a report from the InternationalRetinoblastoma Staging Working Group. Pediatr Blood Cancer 50(3):692-694.https://doi.org/10.1002/pbc.21427

27. Abramson DH. 2018. Re: Skalet et al. Screening children at risk for retinoblastoma: consensus report from the American association of ophthalmic oncologists and pathologists(Ophthalmology. 2018;125:453-458). Ophthalmology 125(9):e63-e64.https://doi.org/10.1016/j.ophtha.2018.03.029 